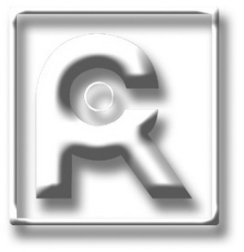

\title{
La educación en radiología en época de pandemia
}

Para participar en el foro sobre pandemia y radiología organizado por Health4theworld, y con el apoyo de la Asociación Colombiana de Radiología, de los jefes de programas de radiología e imágenes diagnósticas en el país y de algunos de sus profesores y residentes, llevé a cabo una pequeña encuesta sobre lo que ocurrió con la educación en radiología en Colombia durante los primeros meses de la pandemia por COVID-19, entre marzo y julio de 2020.

En Colombia existen 16 programas de residencia en radiología. La información que describo es la obtenida de 14 de ellos, correspondiente a unos 200 estudiantes de la especialidad, de universidades tanto públicas como privadas.

La edad promedio de los residentes es de 28 años, y pocos de ellos tienen hijos o padres a su cargo o con los que convivan. Estos últimos factores podrían hacer que los residentes cambiaran su lugar de residencia o que, eventualmente, requirieran suspender sus estudios por periodos cortos. Una de las universidades ofrecía para estos residentes un sitio al cual trasladarse a vivir si requerían evitar ser un foco de contagio para sus familiares.

A diferencia de otros países, en la gran mayoría de los programas de radiología en Colombia no se les pidió que se trasladaran a otras áreas de su hospital, como urgencias o unidades de cuidado intensivo, para apoyar a otras especialidades en la atención de pacientes.

En Colombia, en contraste con otros países, las ecografías son hechas directamente por los radiólogos y no por tecnólogos. Además, la práctica de imágenes diagnósticas para pacientes con COVID 19 que requieren contacto directo, ecografías y procedimientos de intervencionismo mayor o menor en general se lleva a cabo en los hospitales directamente por los médicos radiólogos de las instituciones, sin participación directa de los residentes, como una medida de protección al residente.

Las universidades y los hospitales de práctica dieron a los residentes los elementos de protección personal si ellos los requirieron.

En Colombia se decretó una estricta cuarentena al inicio de la pandemia, lo cual resultó en una drástica disminución en el volumen de los pacientes y procedimientos en los departamentos de radiología hospitalarios y ambulatorios, donde los residentes llevan a cabo sus prácticas. Uno de los centros de diagnóstico por imágenes tuvo, por lo tanto, que cerrar temporalmente sus prácticas y decretar vacaciones durante dos meses, tanto a sus radiólogos como a sus residentes.

Se disminuyó o se canceló la asistencia presencial a los sitios de práctica en diferentes grados y se desarrollaron estrategias para usar herramientas virtuales en educación.

La telerradiología fue utilizada por varios hospitales, aunque aún no todos cuentan con esta herramienta de trabajo virtual. La partici- pación de los residentes en este trabajo virtual dependió de las características de los sistemas de archivo y comunicación de imágenes (PACS, por su sigla en inglés), que en general se modificaron o se actualizaron para optimizar el trabajo virtual en radiología y también en algunos de ellos para lograr que este trabajo permitiera incluir a los educandos. Los hospitales hicieron cambios ingeniosos para preservar la práctica educativa de los residentes de manera virtual. En algunos, cada uno de los docentes fue el "padrino" de un residente, quien podía comunicarse con su docente durante la lectura. Otros utilizaron simultáneamente plataformas virtuales de comunicación para poder compartir la interpretación de los estudios de imágenes. El volumen de práctica se redujo significativamente también en aquellas áreas que requieren la presencia del radiólogo, como la ecografía, los exámenes con fluoroscopia y los procedimientos guiados por imágenes diagnósticas.

La programación de las rotaciones de los residentes se tuvo que modificar, de tal manera que se cancelaron o pospusieron las prácticas que requieren presencialidad, como ecografía, fluoroscopia y procedimientos, al igual que la rotación de mamografía. En algunos hospitales los procedimientos guiados por imágenes se incrementaron en volumen, pues los pacientes con enfermedades como apendicitis, diverticulitis o abscesos de cuello consultaron tardíamente al hospital por temor al contagio y se presentaron con estadios avanzados de sus enfermedades infecciosas o con abscesos en abdomen o en el cuello, y se beneficiaban de intervenciones percutáneas. También en unidades de cuidado intensivo o en urgencias se requirió más a menudo la intervención del radiólogo, por ejemplo, para guiar la inserción de catéteres. En algunos hospitales la práctica hospitalaria de las ecografías convencionales se mantuvo o aumentó, debido al mayor requerimiento de dichas ecografías para los pacientes con COVID-19 o, en algunos casos, como soporte a los médicos de otras especialidades en sus consultas virtuales a pacientes de medicina interna, urología o medicina familiar. Sin embargo, en general esto no incrementó la práctica del residente en las áreas de procedimientos y ecografía. Entonces, en la mayoría de los hospitales, estas rotaciones fueron reemplazadas por prácticas como la lectura de estudios de radiología convencional, tomografía computarizada o resonancia magnética. La práctica de mamografía, fundamentalmente ejercida en el ámbito ambulatorio, también se redujo en un grado significativo.

Por medidas de bioseguridad, las rotaciones electivas programadas a los residentes, en particular aquellas realizadas en hospitales fuera del país, también fueron canceladas o pospuestas, pues dichos hospitales cerraron el ingreso de médicos extranjeros. Todo esto con- 
dujo a un cambio en la programación de vacaciones de los residentes, por ejemplo, mediante el adelanto forzoso de vacaciones de este y el próximo año.

El traslado a la virtualidad en la mayoría de las instituciones condujo a un mayor número de actividades teóricas, como revisiones de tema, presentaciones de casos, seminarios y clubes de revistas, en favor de la educación. Algunos hospitales adquirieron programas que permiten la educación virtual en radiología con acceso a revisión de casos y, en general, todos utilizaron los recursos virtuales existentes en la radiología académica del mundo para la educación.

La Asociación Colombiana de Radiología organizó y presentó cursos virtuales de actualización en áreas como neurorradiología, ultrasonido de emergencias, mamografía y, en particular, en la educación en radiología torácica, que requería un conocimiento urgente y actualizado de las manifestaciones pulmonares del COVID-19. Dichos cursos se llevaron a cabo con profesores extranjeros y nacionales. Los residentes, como miembros transitorios de la Asociación, pudieron tomar algunos de esos cursos. En otros casos, los programas invitaron a profesores que habían sido sus alumnos a participar en la educación virtual de los residentes en temas relacionados con la pandemia.

Esto fue percibido por todos como un hecho favorable, que se reflejó en un mejor rendimiento en los exámenes teóricos en algunos programas. Algunos residentes tuvieron la oportunidad de asistir a los congresos internacionales virtuales de la especialidad.

También se convirtieron en virtuales las reuniones departamentales e interdepartamentales, principalmente aquellas de toma de decisiones y de presentación de casos, las cuales son un muy buen recurso educativo para los residentes. Se encontró una mayor participación de los profesores, tanto de radiología como de otras áreas en dichas reuniones, aspecto que favorece su éxito. Sin embargo, la percepción de los residentes y profesores ha sido que el trabajo puramente virtual es agotador y no logra reemplazar completamente la educación presencial.

Al mirar el bienestar y la salud mental de los residentes, en menos de la mitad de los programas llevaron a cabo encuestas para conocer este aspecto durante la pandemia y la cuarentena. Otro tanto incrementó la comunicación entre los jefes de los programas y los residentes para estar atentos a la salud mental de los estudiantes de posgrado. Las universidades incrementaron el apoyo a la salud mental con programas psicológicos, la posibilidad de una consulta psiquiátrica o psicológica telefónica y el desarrollo de programas de ejercicio o yoga.

Uno de los programas académicos ofreció y estimuló la participación de los estudiantes en espacios lúdicos, dirigidos y apoyados por neuropsicología. En otro se incrementaron las reuniones de tipo grupo Balint. Algunos de los residentes de radiología los usaron, otros no los conocían, o si los conocían, no los usaron. La mitad de los directores de los programas de radiología en Colombia no percibieron problemas de salud mental en sus residentes.

Los residentes presentaron miedo y ansiedad relacionados con el desconocimiento de la enfermedad por el temor de contagiar a sus familiares. Así mismo, percibieron incertidumbre sobre el futuro de su educación al no alcanzar las metas educativas de sus programas y no lograr un entrenamiento adecuado, lo cual, por supuesto, fue proporcional a la reducción del volumen de trabajo. Refirieron incerti- dumbre por lo que será el trabajo en radiología en el futuro próximo y remoto. En algunos de ellos, esto se manifiesta como ansiedad, fatiga, estrés y enojo.

El viraje a la práctica y la educación virtual genera o aumenta el agotamiento, que ya era alto entre los médicos radiólogos y los residentes de esta especialidad. Al mismo tiempo, se reconoce que esto puede aprovecharse para incrementar la camaradería y una mayor participación en el apoyo a los médicos de otras especialidades en la toma de decisiones, lo cual puede impactar positivamente el cuidado de los pacientes. Una pequeña minoría de residentes decidió aplazar su formación.

Al final, vemos entonces que la educación en radiología también se vio impactada por la pandemia del COVID-19. El objetivo consiste en lograr un equilibrio entre mantener su seguridad y bienestar y alcanzar las metas clínicas y académicas para lograr un entrenamiento adecuado de los médicos residentes, de tal manera que sean competentes como radiólogos en el futuro próximo, que seguramente no será igual al tradicional.

Al educar en pandemia, hemos aprendido a adaptarnos a situaciones nuevas, sean estas favorables o no. Los retos han sido aprovechados para ser creativos e innovar, utilizando recursos virtuales antes poco conocidos o explotados. Probablemente permanecerán en la educación las habilidades y recursos de lo virtual adquiridos durante la pandemia, útiles no solo para la educación, sino también para proporcionar valores agregados a la atención de los pacientes, papel que los radiólogos debemos desempeñar cada vez más a menudo.

Las competencias como el conocimiento de las nuevas enfermedades relacionadas con la pandemia, que antes desconocíamos, deben estar ahora presentes. Hemos aprendido que estar aislados no significa estar incomunicados y que la comunicación es un elemento fundamental para el bienestar de los radiólogos y de los residentes, que puede crear asociaciones productivas, por ejemplo, para compartir los conocimientos.

Conocer de la salud mental de los residentes es muy importante, ya que, al igual que en otros profesionales, esta puede deteriorarse con la pandemia. En este aspecto, los recursos virtuales como medios para usar y compartir actividades lúdicas y de ejercicio físico, o para buscar ayudas especializadas si se requieren, son también muy útiles.

Sonia Bermúdez M. Editora revcolradiología@gmail.com 